\title{
ESTIMATION OF REST PERIODS FOR NEWLY CONSTRUCTED/RECONSTRUCTED PAVEMENTS
}

\author{
Anwaar Ahmed ${ }^{1}$, Tariq Usman Saeed ${ }^{2}$, Samuel Labi ${ }^{3}$ \\ ${ }^{1}$ School of Civil and Environmental Engineering, National University of Science and Technology, \\ Islamabad, Pakistan \\ ${ }^{2,3}$ Lyles School of Civil Engineering, Purdue University, West Lafayette, United States
}

Submitted 10 April 2015; resubmitted 7 June 2015, 6 August 2015; accepted 5 September 2015

\begin{abstract}
Newly-constructed and reconstructed highway pavements under the effect of traffic loading and climatic severity deteriorate progressively and need preservation intervention after a certain number of years following their construction. In the literature, the term 'rest period' has been used to refer to the number of years that elapse between the construction completion to the application of first major repair activity. The rest period is a critical piece of information that agencies use to not only plan and budget for the first major repair activity but also to develop more confidently, their life-cycle activity schedules for life cycle costing, work programming, and long-term plans. However, the literature lacks established procedures for predicting rest periods on the basis of pavement performance thresholds. In the absence of such resources, highway agencies rely mostly on expert opinion for establishing the rest periods for their pavement sections. In addressing this issue, this paper presents a statistical methodology for establishing the rest periods for newly-constructed or reconstructed pavements. The methodology was demonstrated using empirical data from in-service pavements in a Midwestern State in the US. The paper's results show that the rest periods of newlyconstructed and reconstructed highway pavements are significantly influenced by their functional class, surface material type, traffic loading level, and climate severity.
\end{abstract}

Keywords: road; highway; transport management; transport planning; rest period.

\section{Introduction}

Highway pavements are designed and constructed for providing service for a long period of time. Like most other civil structures and facilities, it can be assumed that highways are constructed so that user can benefit for an infinite time period and if need arises can be reconstructed repeatedly after reaching design life. After construction of a highway, routine and periodic maintenance, rehabilitation and reconstruction are the major activities that are performed to ensure that the highway pavements continue to provide reasonable serviceable conditions. An effective pavement preservation program specifies the appropriate times at which different Maintenance and Rehabilitation (M\&R) treatments should be applied to the pavement structure and helps agencies quantify the total maintenance needs of entire network (Parida et al. 2005). In present era pavement managers strive to adopt systematic preservation strategies that are optimal so that intervention applied to any asset are neither too early (asset in relatively good condition) nor too late (asset highly deteriorated) (Khurshid et al. 2011;
Jain et al. 2014). In addition, highway agencies strive to minimize the life cycle maintenance cost while ensuring reasonable level of ride quality (Meneses et al. 2013).

Reliable information of future pavement performance is needed for planning M\&R activities and for ensuring adequate funding. Accurate information on initial pavement performance or rest period is also needed by highway agencies for Life Cycle Cost Analysis (LCCA) procedures and formulation of Maintenance, Rehabilitation and Reconstruction (MR\&R) strategies. MR\&R strategy is the combination of different maintenance treatments applied over pavement life cycle (Ahmed et al. 2013, 2015). LCCA is routinely performed by highway agencies for pavement type selection (flexible vs. rigid) and to access the lifecycle preservation cost of alternate pavement repair options (Rangaraju et al. 2008). Similarly, highway pavements preservation strategy formulation requires knowledge of the initial pavement performance and the effectiveness of subsequent $M \& R$ treatments and both have significant impact on overall cost of MR\&R strategy. For similar traffic and climatic loadings, MR\&R strategies with longer intervals

Corresponding author: Anwaar Ahmed

E-mail: dranwaar@scee.nust.edu.pk 
between M\&R activities will generally have lower total agency costs (the sum of reconstruction, rehabilitation and maintenance activities) as compared to strategies with shorter intervals (Ahmed 2012). A number of studies in the past have estimated the effectiveness of different M\&R treatments (Hall et al. 2002; Labi, Sinha 2003; Khurshid et al. 2014); however, relatively little effort has been made to estimate the initial performance period of newly constructed/reconstructed pavements, which is referred to as the 'rest period' in this paper (the time from opening the newly constructed/reconstructed road to traffic to the time of application of the first periodic maintenance treatment) (Fig. 1). Periodic maintenance or preventive maintenance treatments are used to retard the pavement deterioration and to correct minor defects and improve functional condition e.g. chip sealing, microsurfacing and thin Hot-Mix Asphalt (HMA) overlay (FHWA 2005b). Past studies have provided time-based estimates for rest period of flexible and rigid pavements (Lamptey et al. 2005; Li, Kaini 2007; Rangaraju et al. 2008; InDoT 2011b); however, an explicit analysis of rest periods using empirical data on pavement performance, has not been carried out in the literature. Thus, the literature lacks estimates of rest periods or established procedures for their prediction. In the absence of such resources, highway agencies rely on expert opinion for establishing the rest periods for their pavement sections. In Section 1 of this paper, we present a wider discussion of the literature regarding the estimation or specification of pavement rest periods.

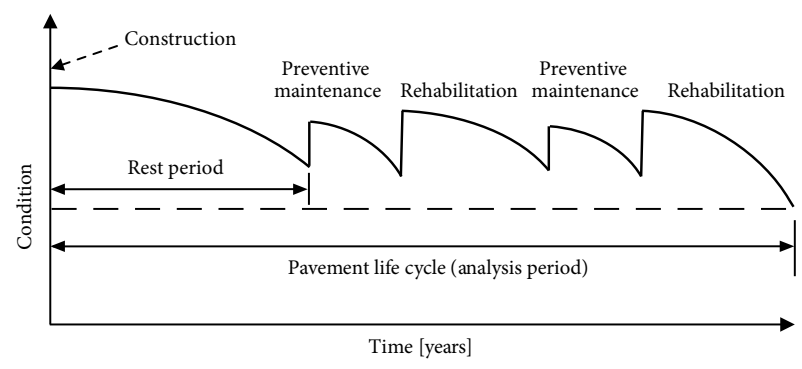

Fig. 1. Pavement rest period

In addressing this issue, this paper presents a statistical methodology for establishing the rest period of newly constructed or reconstructed pavements using data on performance and also on the factors that affect performance. The methodology was demonstrated using empirical data from in-service roads in a Midwestern state in the US. The paper also seeks to investigate whether the rest period for a newly constructed and reconstructed highway pavement is significantly influenced by characteristics of the pavement section and its environment, including their functional class, surface material type, traffic loading level, and climate severity.

\section{Literature Review}

To establish treatment types and timings, different studies in the past have used different timing criteria (age or condition) and different basis for establishing these criteria levels (historical trends, expert opinion or optimization). The commonly used procedures are discussed as follows.

\subsection{Time-Based Strategy}

A time-based strategy is one where treatments are applied on the basis of pavement age. Such a strategy usually involves the use of the treatment service life and is also termed as a strategy based on 'preset time intervals' (Lamptey et al. 2005). The treatment application interval may be large or small depending upon the asset age, traffic, and climate. Hicks et al. (2000); Zimmerman et al. (2002); Labi, Sinha (2003) and Lamptey et al. (2005) are the prominent studies which formulated time-based strategies for flexible and/or rigid pavements for such purposes as maintenance treatments cost-effectiveness evaluation and/or preparation of pavement preservation strategies. Mostly these strategies were developed using expert opinion e.g. responses of pavement engineers to a questionnaire survey. In a study that involved thirtytwo states in the US, Rangaraju et al. (2008) determined that most of the states, at the time, were using expert opinion for establishing the rest periods for their flexible and rigid pavements; also, most of the states use a single value of rest period without accounting for differences in highway pavement sections in terms of their functional class, traffic loading, or location (climate severity). For example, for flexible pavements, the different states use the following rest periods (years): Alabama - 12, Arkansas - 20, Florida - 20, Kansas - 10, Louisiana 15, Mississippi - 12, and North Carolina - 10; for rigid pavements, they use the following rest periods (years): Alabama - 20, Arkansas - 20, Florida - 20, Kansas - 20, Louisiana - 20, Mississippi - 16, and North Carolina 15. However, some states have gone further to specify a range for their rest period instead of a single value; for example, for flexible pavements, Colorado and Minnesota use rest periods that range between $10-12$ years and 15-20 years, respectively.

\subsection{Performance-Based Strategy}

In performance-based strategy formulation, the pavement threshold condition is the deciding factor for pavement intervention. As soon as the pavement reaches a certain threshold condition in terms of a selected performance indicator, an appropriate preventive maintenance, rehabilitation, or reconstruction is carried out to restore the pavement condition. Various studies in the past have developed performance-based thresholds and strategies using engineering judgment/past experience (Ahmad 2004; Lamptey et al. 2005; AI\&T 2006) and analytical approach (Khurshid 2010), however none of the past studies explicitly established pavement rest periods for different pavement types on different highway functional classes.

\subsection{Use of Decision Trees and Matrices}

Condition-based decision trees and matrices are a set of rules and criteria, which are established either by expert opinion or past experience in pavement management 
(FHWA 1990; Khurshid 2010; Labi et al. 2005). These are used for selecting appropriate $M \& R$ treatment and have been developed by a number of studies in the past (Wade et al. 2001; MnDoT 2001; Ahmad 2004; AI\&T 2006; Dell'Acqua et al. 2012). Most of the past studies on use of decision trees and matrices discuss the application timing of different M\&R treatments but timing of application of first treatment after construction (rest period) is based on expert opinion (Labi, Sinha 2003; Lamptey et al. 2005; Li, Kaini 2007).

\section{Study Methodology}

In this study, an analytical approach was used to establish the rest period, which is discussed in ensuing paragraphs and generalized framework is shown in Fig. 2.

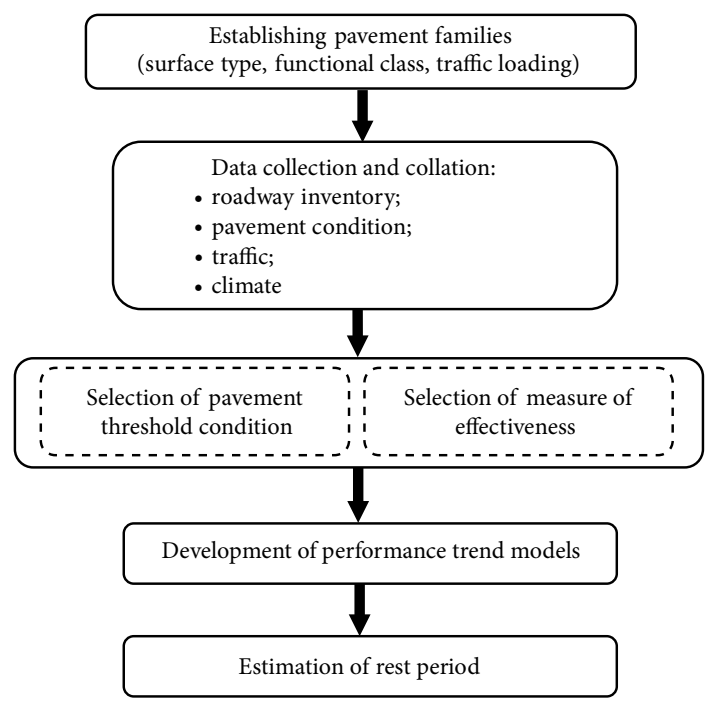

Fig. 2. Generalized framework for estimation of pavement rest period

\subsection{Establishing Pavement Families}

In this paper, it was hypothesized that rest periods will be different for different characteristic of the pavement section as well as their environment. Therefore, the pavements were placed into different families on the basis of their surface type (flexible and rigid), functional class (Interstate and National Highway System (Non-Interstate) (NHS(NIS))), and loading intensity. The pavements were further subdivided on the basis of truck traffic volume. Past research (for example, Khurshid et al.
2014) suggests that pavements with high truck traffic are generally expected to have significantly shorter rest periods.

\subsection{Data Preparation}

Empirical data from in-service roads mostly in the northern part of a Midwestern state in the US were collected. This was for a number of road segments, and the data spanned from 1994 to 2006. The major data items include road inventory, pavement condition, contract information, traffic, and climate. The road inventory data provided basic information about contract identification, start and ending points, functional class, and county and district locations. Contract data from the highway agency database, which provided information on newly constructed and reconstructed pavements includes: contract identification number and location, letting year, number of lanes, and project length. Climate was an important variable in present study. The influence of climate on pavement condition is well documented in the literature (FHWA 1990, 2005a; Hall et al. 2002; Peterson 1985; Žilioniene et al. 2013). In the present study, climate data included the freeze index, annual number of freeze thaw cycles, average annual precipitation, and average number of wet days in a year, and were obtained from INDIPAVE 2000 (Labi 2001), a database established using data from the National Oceanic and Atmospheric Administration online climate database. Traffic data, which included the Annual Average Daily Traffic (AADT) and Truck AADT, were obtained from traffic monitoring sections (InDoT 2011a). The details of the traffic and climate data are provided in Table 1 for the two highway functional classes and the two pavement material types. All data elements were carefully analyzed to exclude extreme observations (outliers) using $3 \sigma$ method. Filtering of anomalous observations ensures the homogeneity of data used for model estimation (Dell'Acqua et al. 2013).

The pavement condition data included the IRI. IRI is the deviation of a subject pavement surface from a true planner surface and is measured using an instrumented vehicle (Fig. 3) equipped with non-contact sensors (infrared, lazer or acustic etc.) and accelerometers. Variations in vertical distance from a horizontal plane of reference (accelerometers) are recorded by sensors (Sayers, Karamihas 1998; Ong et al. 2010a, 2010b). In this study, the IRI served as the performance indicator for a number of reasons: first, it is widely used as a basis for pave-

Table 1. Summary statistics of key variables

\begin{tabular}{|l|l|c|c|c|c|c|c|c|}
\hline \multirow{2}{*}{$\begin{array}{c}\text { Pavement } \\
\text { type }\end{array}$} & $\begin{array}{c}\text { Highway } \\
\text { functional } \\
\text { class }\end{array}$ & \multicolumn{2}{|c|}{$\begin{array}{c}\text { Annual Average } \\
\text { Daily Traffic } \\
\text { (AADT) }\end{array}$} & \multicolumn{2}{|c|}{$\begin{array}{c}\text { Average Annual } \\
\text { Freeze Index (AAFI) } \\
\text { [degree-days] }\end{array}$} & \multicolumn{2}{c|}{$\begin{array}{c}\text { International } \\
\text { Roughness Index } \\
\text { (IRI) [m/km] }\end{array}$} & \multicolumn{2}{|c}{$\begin{array}{c}\text { Geographical location } \\
\text { (Indiana county) }\end{array}$} \\
\cline { 3 - 11 } & Mean & S.D. & Mean & S.D. & Mean & S.D. & \\
\hline \multirow{2}{*}{ Flexible } & Interstate & 8220 & 3379 & 248.48 & 229.94 & 1.167 & 0.366 & $2,13,26,40,49,51,61,63,74,87,79$ \\
\cline { 2 - 10 } & NHS(NIS) & 1827 & 758 & 389.71 & 219.67 & 1.28 & 0.29 & $1,9,31,32,36,42,45,51$, \\
\hline \multirow{2}{*}{ Rigid } & Interstate & 9793 & 2660 & 528.25 & 322.85 & 1.82 & 0.54 & $2,10,13,21,31$ \\
\cline { 2 - 9 } & NHS(NIS) & 2320 & 2170 & 596.33 & 125.39 & 1.33 & 0.27 & $34,35,71,79,83,85$ \\
\hline
\end{tabular}




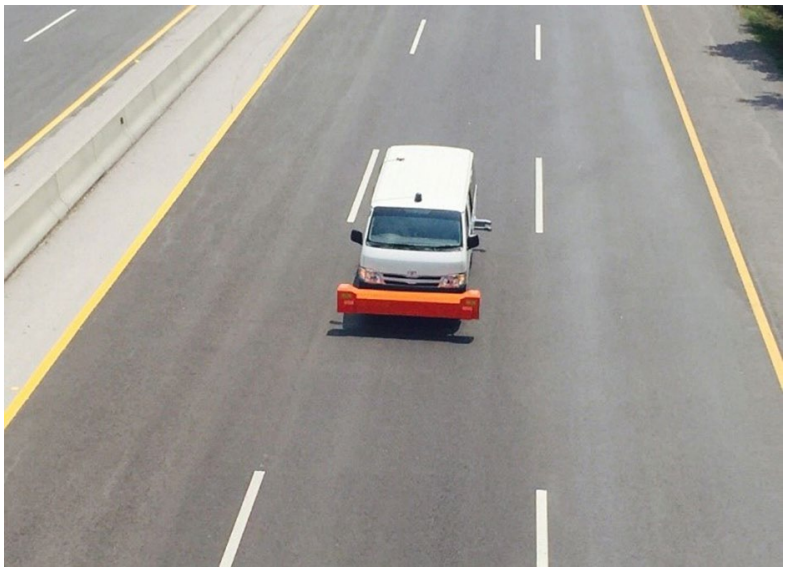

Fig. 3. Pavement roughness data collection using instrumented vehicle

ment preservation decision making; second, it quantifies pavement bumpiness, and thus is indicative of the severity of surface defects; third, it has universal acceptability worldwide (for example, in the US, all highway agencies are required to report IRI of their major highways to the federal government for funding allocations and oversight purposes); and fourth, IRI data is collected by most highway agencies worldwide (Ong et al. 2010a, 2010b). Also, all highway agencies in the US collect IRI data and most have adopted the AASHTO PP 37-04 Standard for IRI data collection (Ong et al. 2010a, 2010b). While, the present study used IRI for estimating the rest periods, the methodology developed in this paper can be applied with any other performance indicator such as specific distresses or composite indicators as used in past studies (Dell'Acqua, Russo 2011).

\subsection{Selection of Pavement Threshold Condition}

Every highway agency maintains a list of standard treatments for carrying out rehabilitation or preventive maintenance of their pavements. For each of these treatments, they specify minimum performance levels that warrant application of the different treatments. For establishing the performance-based rest periods, selecting an appropriate threshold pavement condition is an important step. As Khurshid et al. (2011) pointed out, it is not cost-effective when treatments are applied too early (when the asset is still in the superior performance) or too late (when the asset is in such poor condition that there are excessive user costs). The threshold could be same for all pavement types or could different for the different pavement types and highway functional classes. For example Indiana Department of Transportation (INDOT) pavement design manual recommends that preventive maintenance should be applied to the pavements when IRI $<2.37 \mathrm{~m} / \mathrm{km}$ (150 in/mile) (InDoT 2011b). As discussed in Section 1 of this paper, most highway agencies develop their thresholds in one of two ways: (1) surveys of pavement management experts, or (2) a review of historical data (simple average of pretreatment pavement conditions at time of application of the treatment in question). Such approach may be mis- leading because of the typical wide variations in pavement conditions at times of application that may be earlier or later than the optimal time of application, as this is greatly influenced by the economic conditions and the financial strength of the agency. Recognizing the limitation of expert opinion, Khurshid (2010) used Indiana data and cost-effectiveness analysis to establish optimal thresholds for pavement treatments, and demonstrated, using empirical data from in-service pavements, that inferior cost-effectiveness is achieved if the treatment is applied either too early or too late. In the present study, Khurshid's (2010) threshold IRI values for application of periodic maintenance were used: Interstate $=$ $1.98 \mathrm{~m} / \mathrm{km}(125 \mathrm{in} / \mathrm{mile})$ and NHS(NIS) $=2.052 \mathrm{~m} / \mathrm{km}$ (130 in/mile). These threshold values were established using IRI data measured for each $1.6 \mathrm{~km}$ (one mile) long segment of in service pavements.

\subsection{Selection of Measure of Effectiveness: Intervention (Treatment) Service Life Concept}

The effectiveness of M\&R treatments can be measured by the extent to which a treatment extends the pavement service life or improves ride quality in the short or long term (Smith et al. 1993; Ahmed et al. 2013, 2015). On the other hand, the effectiveness of a newly constructed/ reconstructed pavement can be estimated by determining the time from new construction to the application of the first periodic maintenance (preventive maintenance) treatment (i.e., the rest period). The intervention service life, increase in the area bounded by the performance curve and increased average pavement condition over the intervention service life, are the three most widely used non-monetized measures of treatment effectiveness (Khurshid et al. 2014). Among commonly used measures of treatment effectiveness, treatment service life has more intuitive meaning and is widely used by agencies. It is the time interval between the pavement reconstruction or treatment application and the time taken to reach some threshold (Ahmed et al. 2013, 2015) as shown in Fig. 4.

For rest period estimation, service life was used as the measure of effectiveness because it is consistent with the concept of a rest period. Every agency has an important task of establishing guidelines for pavement M\&R. Having proper pavement M\&R guidelines help in selecting the proper treatments for both flexible and

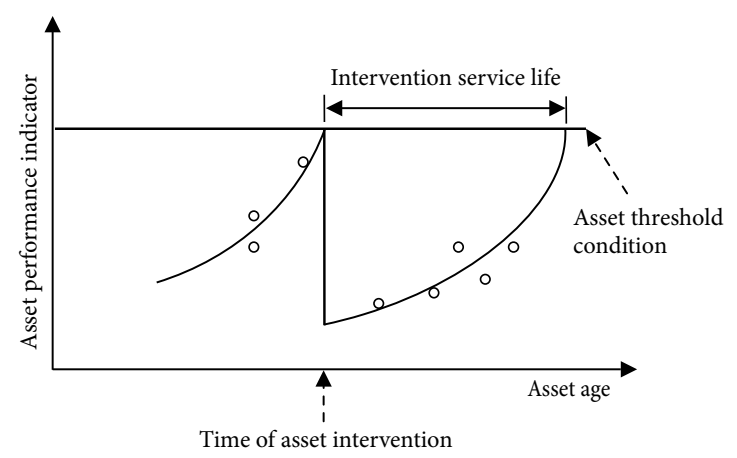

Fig. 4. Schematic representation of intervention service life 
rigid pavements. Reliable information on the treatment service life and the rest period can help in the formulation of pavement M\&R strategies for various agency tasks, including LCCA.

\section{Development of Performance Trend Models and Estimation of Rest Periods}

Ordinary Least Square (OLS) regression was used to develop performance models for both flexible and rigid pavement. Separate models were developed for different highway functional classes depending upon availability of data (e.g. Interstate and NHS(NIS)). The explanatory variables considered for performance modeling are functional classification (surrogate variable for construction and maintenance quality), pavement age (surrogate for combined traffic and climatic loading), truck traffic, and climatic conditions. The functional form of the pavement performance models developed in this paper is shown in Eq. (1). Statistical Analysis System (SAS Institute 2016) was used for the model estimation, and standard model building procedures were used. Using the developed performance models, the expected time from new construction of a pavement to the application of the first periodic maintenance was estimated using Eq. (2). The model results are summarized in Table 2.

$$
y_{i}=\exp \left(\beta_{0}+\beta_{1} \cdot A A D T T \cdot t+\beta_{2} \cdot A A F I \cdot t\right),
$$

where: $y_{i}$ is the value of the pavement performance measure (IRI) for a newly constructed pavement segment $i$ [year.t]; AADTT. $t$ is the product of the Average Annual Daily Truck Traffic [millions] and the time since the pavement was constructed, thus representing the total impact of traffic on the pavement since reconstruction; AAFI-t is the product of the Average Annual Freeze Index [thousands of degree-days] and the time since the pavement was reconstructed, thus representing the total impact of climate on the pavement since new construc- tion/reconstruction. Suppose a pavement segment is 10 years old and is located in a county that has an average freeze index of 200 degree-days, than AAFI. $t$ for this pavement segment is $2000 ; \beta_{0}, \beta_{1}$ and $\beta_{2}$ are the model parameters. Making $t$ the subject of the equation, it is possible to estimate the rest period for an established threshold, if the traffic and climatic loading are known, as follows:

$$
t=\frac{\ln \left(y_{i}\right)-\beta_{0}}{\beta_{1} \cdot(A A D T T)+\beta_{2} \cdot(A A F I)} .
$$

This approach has been widely used in pavement performance modeling in Indiana in the recent past for estimation of M\&R treatments service lives (Labi, Sinha 2003; Lamptey et al. 2005; Ong et al. 2010a, 2010b).

\section{Model Results and Discussion}

The summary of the model results are presented in Table 2. All the estimated models have reasonable fit for the rather highly varied data that were collected for different pavement segments from 1994-2006. The $R^{2}$ values ranging from 0.55 to 0.88 indicate that an approximately $55-88 \%$ variance in data is explained at a 95\% level of confidence by these models. Coefficients of both AADTT and AAFI have intuitive signs that is consistent with past studies that used similar approach for pavement performance modeling (Labi, Sinha 2003; Ong et al. 2010a, 2010b). The positive sign of coefficient for AADTT indicates that all else being equal, pavement segments associated with higher traffic loading (truck traffic) deteriorate at a faster rate. Similarly, the positive sign of coefficient for cumulative climatic effect indicates that pavement segments located in extreme climatic condition deteriorate at a faster rate as compared to pavement segments located in moderate climatic conditions, all else being equal. In present study AADTT and AAFI are the two significant variables in the final mod-

\begin{tabular}{|c|c|c|c|c|c|c|}
\hline Highway class & Coefficient & Coefficient value & $t$-value & $p$-value & $R^{2}$ & $N^{*}$ \\
\hline \multicolumn{7}{|c|}{ Pavement performance models for flexible pavement } \\
\hline \multirow{3}{*}{ Interstate } & Constant & 3.969 & 235.02 & $<0.0001$ & \multirow{3}{*}{0.74} & \multirow{3}{*}{203} \\
\hline & AADTT & 0.024 & 3.29 & $<0.0001$ & & \\
\hline & AAFI & 0.052 & 13.84 & $<0.0001$ & & \\
\hline \multirow{3}{*}{ NHS(NIS) } & Constant & 4.037 & 106.45 & $<0.0001$ & \multirow{3}{*}{0.55} & \multirow{3}{*}{87} \\
\hline & AADTT & 0.137 & 9.18 & $<0.0001$ & & \\
\hline & AAFI & 0.035 & 3.01 & $<0.0001$ & & \\
\hline \multicolumn{7}{|c|}{ Pavement performance models for rigid pavement } \\
\hline \multirow{3}{*}{ Interstate } & Constant & 4.386 & 261.01 & $<0.0001$ & \multirow{3}{*}{0.82} & \multirow{3}{*}{126} \\
\hline & AADTT & 0.015 & 18.82 & $<0.0001$ & & \\
\hline & AAFI & 0.005 & 2.59 & $<0.0108$ & & \\
\hline \multirow{3}{*}{ NHS(NIS) } & Constant & 4.131 & 249.85 & $<0.0001$ & \multirow{3}{*}{0.85} & \multirow{3}{*}{88} \\
\hline & AADTT & 0.009 & 2.09 & 0.0394 & & \\
\hline & AAFI & 0.089 & 9.24 & $<0.0001$ & & \\
\hline
\end{tabular}

Table 2. Pavement performance models

Note: ${ }^{*}$ is the sample size (number of observations used for mode estimation). 
els, however there can be additional variables that may play an important role in determining the rest period. In agencies where detailed data on other factors such as initial pavement condition and pavement strength, etc., are available for each pavement section in the network, these variables can easily be included in future modeling efforts for rest period estimation. Doing this will further improve the $R^{2}$ values.

As the 'Crossroads of America', Indiana facilitates freight movement in both North-South and East-West directions, serving the economy of not only state, but also the nation as a whole (InDoT 2007). The volume of truck traffic continues to increase in Indiana as the state's transportation infrastructure provides companies with a more competitive advantage in moving freight through the state, compared with other modes (InDoT 2007; Indiana Logistics 2008). In Indiana, there is marked difference in the level of traffic loading within and between the major highway functional classes. Some Interstate routes have over 30000 truck AADT while few state routes have less than 50 trucks per day. It is generally observed that all Interstates are associated with much higher levels of truck traffic compared to NHS(NIS). Also, most US routes (NHS(NIS) have comparatively higher truck traffic compared to state roads (InDoT 2011a). These wide variations in pavement loading patterns demands that, for rest period estimation, not only should the pavement segments be divided on the basis of surface type, functional class, or route type, but also on the basis of traffic loading.

The rest periods were estimated using the methodology described earlier using four different truck traffic levels and three different climatic severity levels. Level of climatic severity was defined on the basis of AAFI [degree-days] that are: High Climatic Severity (HCS) (AAFI $\geq 650)$, Medium Climatic Severity (MCS) $(650 \leq$ AAFI $\geq 450$ ) and Low Climatic Severity (LCS) (AAFI $\leq$ 450). Table 3 presents the estimated rest period for the different highway pavement material types (flexible and rigid), the different highway functional classes, the different levels of traffic loading, and the different levels of climate severity. Table 3 (Fig. 5) indicates that for both
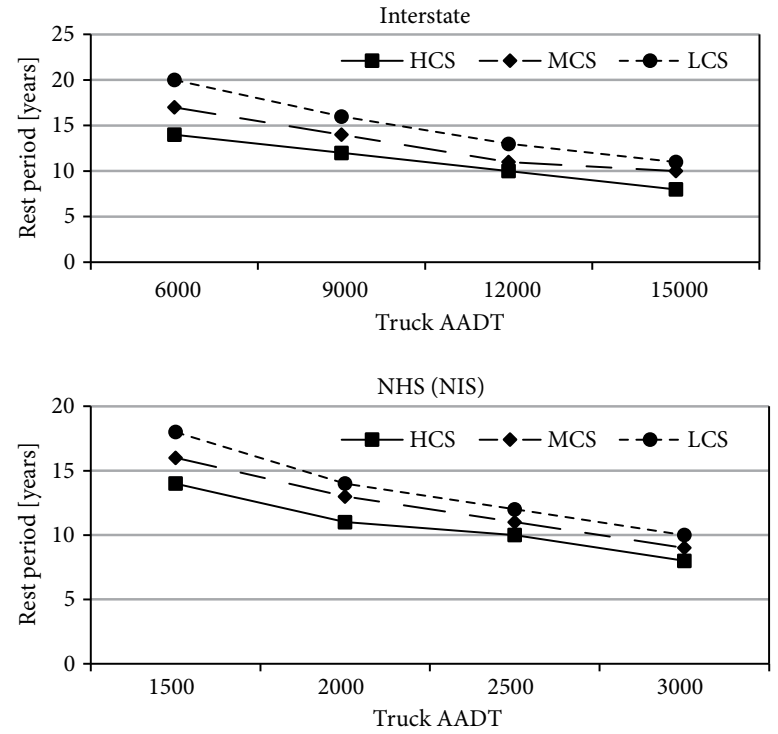

Fig. 5. Estimated rest periods for flexible pavements

Interstate and NHS(NIS), there are substantial rest periods at low traffic, however with increasing traffic levels and/or climatic severity, the rest period keeps on decreasing, indicating that initial pavement performance is quite sensitive to both traffic loading and climatic severity.

It was also revealed that rest periods values for both these functional classes (Interstate and NHS(NIS)) are comparable, although Interstate usually have much higher construction standards as compared to NHS(NIS). This dichotomy can be attributed to much higher traffic loading on Interstate highways compared to NHS(NIS). Therefore, those pavement segments that are located in high traffic loading zone and/or severe climatic regions need first periodic maintenance treatment much earlier in their service life compared to pavement segments located in regions having low traffic levels and/ or low severe climatic. For example, Interstate 80/90, which passes through the northern portion of Indiana, has certain segments with truck AADT of over 40000 (InDoT 2011a) indicating that newly constructed pave-

Table 3. Rest periods for flexible and rigid pavements

\begin{tabular}{|c|c|c|c|c|c|c|c|}
\hline \multicolumn{4}{|c|}{ Interstate } & \multicolumn{4}{|c|}{ NHS(NIS) } \\
\hline AADTT & HCS & MCS & LCS & AADTT & HCS & MCS & LCS \\
\hline \multicolumn{8}{|c|}{ Rest periods for flexible pavements } \\
\hline 15000 & 8 & 10 & 11 & 3000 & 8 & 9 & 10 \\
\hline 12000 & 10 & 11 & 13 & 2500 & 10 & 11 & 12 \\
\hline 9000 & 12 & 14 & 16 & 2000 & 11 & 13 & 14 \\
\hline$<6000$ & 14 & 17 & 20 & $<1500$ & 14 & 16 & 18 \\
\hline \multicolumn{8}{|c|}{ Rest periods for rigid pavements } \\
\hline 15000 & 10 & 10 & 11 & 3000 & 12 & 17 & 20 \\
\hline 12000 & 12 & 13 & 13 & 2500 & 12 & 17 & 20 \\
\hline 9000 & 16 & 17 & 17 & 2000 & 12 & 17 & 20 \\
\hline$<6000$ & 20 & 20 & 20 & $<1500$ & 13 & 18 & 20 \\
\hline
\end{tabular}


ment segments at such locations will need preventive maintenance treatment very early in their design lives. As such, in designing long-term $M \& R$ schedules for pavement segments, it is not appropriate to use average rest periods for all the pavement segments irrespective of their functional class and climate regions as is currently done in highway agencies.

The paper also analyzed the sensitivity of rest period length to climate severity and traffic loading (Fig. 5). The results indicated that rest period is more sensitive to traffic loading compared to climate severity. For example for rigid Interstate pavement with traffic loading of 15000, the estimated rest periods are 10,10 and 11 years for HCS, MCS and LCS, respectively. However, when traffic level is changed to 12000 , estimated rest periods are 12,13 and 13 years for HCS, MCS and LCS, respectively.

Also for the rigid pavements, rest periods were estimated for the two highway functional classes (Interstate and NHS(NIS)). In case of rigid pavements (Table 3 and Fig. 6), trends were similar to flexible pavement. However, at similar traffic levels, rigid pavements rest periods were higher as compared to flexible pavements, which is intuitive. For Interstate pavement segments, rest period's ranged from 8 to 20 years. In the practice, rigid pavement rest periods have been estimated as high as 20 years or more. For rigid Interstate pavement segments, that have comparatively low traffic (6000 trucks per day), estimated rest periods are closer to the current INDOT estimated service life of newly-constructed rigid pavement (InDoT 2011b); however for pavement segments located in high traffic regions/zones the paper's results suggest that the estimated rest periods are much lower; this reinforces the need for highway agencies to establish different performance-based rest periods for the different highway functional classes, traffic loading levels, and climate severity levels of their pavements. For
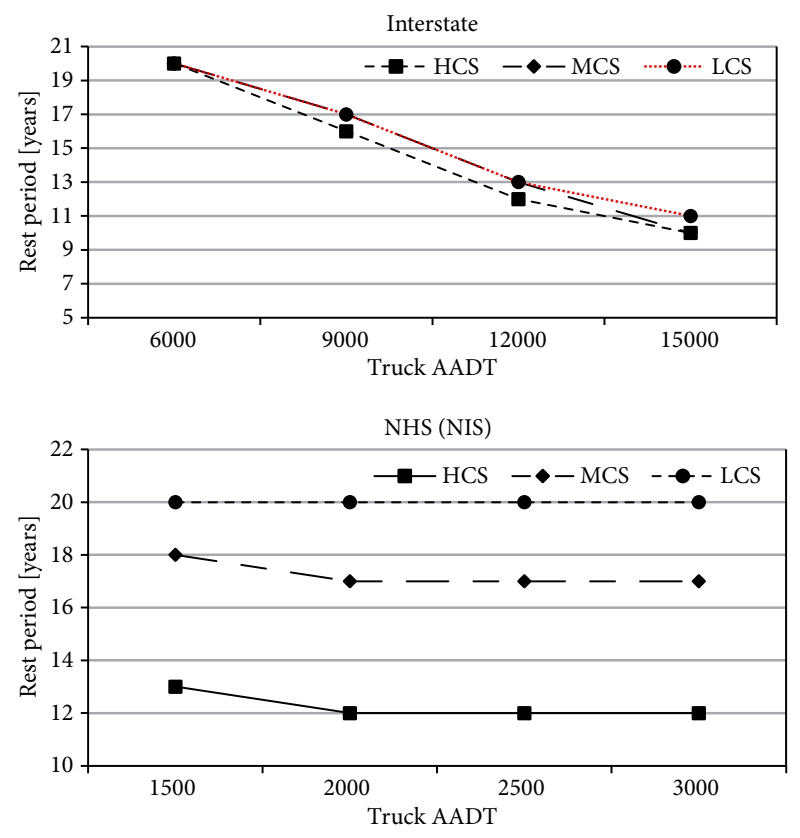

Fig. 6. Estimated rest periods for rigid pavements
NHS(NIS) rigid pavement segment, the models yielded almost similar rest periods; this may be attributed to the lower traffic levels on NHS(NIS) highways compared to Interstate highways. The analysis showed that even a $100 \%$ increase in traffic loading (from 1500 to 3000 ) lowers the rest period by only one year for NHS(NIS) rigid pavement segment. However, at similar traffic levels (3000), but different level of climatic severity, there is wide variation in estimated rest periods for NHS(NIS) rigid pavement segments; indicating that estimated rest periods are very sensitive to climatic severity for this particular highway class.

\section{Summary and Conclusions}

For planning and programming long-term pavement preservation, pavement managers strive to access the effectiveness of initial pavement performance and different maintenance treatments.

This paper presented a methodology for establishing the rest period of newly constructed/reconstructed pavements using well-established concept of treatment service life. Using data from a Midwestern state in the US, rest periods were established for flexible and rigid pavements on the Interstate and NHS(NIS) functional classes.

These rest periods were estimated using a threshold IRI of $1.98 \mathrm{~m} / \mathrm{mm}(125 \mathrm{in} / \mathrm{mile})$ for Interstate and $2.052 \mathrm{~m} / \mathrm{km}$ (130 in/mile) for NHS(NIS) pavements, respectively.

The results suggest that the rest period for flexible pavements on Interstates is $8-20$ years, and on NHS(NIS), 8-18 years, depending on the levels of traffic loading and climate severity. Also, the rest period for rigid pavements on Interstates is 10-20 years, and for NHS(NIS), 12-20 years. These results indicate that the rest period estimate for a given pavement section is significantly affected by its highway functional class, its traffic loading level, and the climate severity of the region where it is located. Specifically, there is a nonlinear relationship between pavement rest periods and its traffic loading or climate severity.

The rest period values obtained in present study can be used by highway agencies as a guide for formulating or revising their schedules of rehabilitation and maintenance of new or proposed pavements, long-term planning, budgeting, and needs assessment, and LCCAevaluation of pavement design and maintenance alternatives.

The results of the present study provide guidelines for highway agencies to establish the rest periods for their jurisdictions using same or different performance indicator for which data is usually collected by highway agency.

\section{Acknowledgements}

The authors acknowledge the assistance of pavement management personal at Indiana Department of Transportation (INDOT) for their help in data collection. 
The funding for the present study was provided by the Indiana Department of Transportation (INDOT) and Federal Highway Administration (FHWA) through Purdue University's Joint Transportation Research Program.

\section{References}

AASHTO PP 37-04. Standard Practice for Determination of International Roughness Index (IRI) to Quantify Roughness of Pavements.

Ahmad, M. Z. 2004. A Framework for Selecting Pavement Preservation Strategies Using Life Cycle Cost Analysis: MSc Thesis. Purdue University, US. 206 p.

Ahmed, A. 2012. Pavement Damage Cost Estimation Using Highway Agency Maintenance, Rehabilitation, and Reconstruction Strategies: PhD Dissertation. Purdue University, US. 340 p.

Ahmed, A.; Bai, Q.; Labi, S. 2015. Pavement damage cost estimation: a synthesis of past research, Proceedings of the Institution of Civil Engineers - Transport 168(1): 48-58. http://doi.org/10.1680/tran.12.00075

Ahmed, A.; Labi, S.; Li, Z.; Shields, T. 2013. Aggregate and disaggregate statistical evaluation of the performance-based effectiveness of long-term pavement performance specific pavement study-5 (LTPP SPS-5) flexible pavement rehabilitation treatments, Structure and Infrastructure Engineering: Maintenance, Management, Life-Cycle Design and Performance 9(2): 172-187.

http://doi.org/10.1080/15732479.2010.524224

AI\&T. 2006. Guidelines for Assessing Pavement Preservation Treatments and Strategies. Alberta: Infrastructure and Transportation (AI\&T), Canada. 58 p. Available from Internet: http://www.transportation.alberta.ca/Content/docType233/Production/gappts.pdf

Dell'Acqua, G.; Busiello, M.; Russo, F. 2013. Safety data analysis to evaluate highway alignment consistency, Transportation Research Record: Journal of the Transportation Research Board 2349: 121-128. http://doi.org/10.3141/2349-14

Dell'Acqua, G.; De Luca, M.; Russo, F. 2012. Procedure for making paving decisions with cluster and multicriteria analysis, Transportation Research Record: Journal of the Transportation Research Board 2282: 57-66. http://doi.org/10.3141/2282-07

Dell'Acqua, G.; Russo, F. 2011. Road performance evaluation using geometric consistency and pavement distress data, Transportation Research Record: Journal of the Transportation Research Board 2203: 194-202.

http://doi.org/10.3141/2203-24

FHWA. 2005a. Highway Performance Monitoring System Field Manual for the Continuing Analytical and Statistical Database. Appendix E: Measuring Pavement Roughness. Federal Highway Administration (FHWA), US Department of Transportation, Washington, DC.

FHWA. 2005b. Pavement Preservation Definitions: Memorandum. Federal Highway Administration (FHWA), US Department of Transportation, Washington, DC.

FHWA. 1990. An Advanced Course in Pavement Management Systems. Report FHWA-ED-90-014. Federal Highway Administration (FHWA), US Department of Transportation, Washington, DC.
Hall, K. T.; Correa, C. E.; Simpson, A. L. 2002. LTPP Data Analysis: Effectiveness of Maintenance and Rehabilitation Options. NCHRP Project 20-50[3/4]. National Cooperative Highway Research Program (NCHRP). Transportation Research Board, National Research Council, Washington, DC. 332 p. Available from Internet: http://onlinepubs.trb. org/onlinepubs/nchrp/nchrp_w47.pdf

Hicks, R. G.; Seeds, S. B.; Peshkin, D. G. 2000. Selecting a Preventive Maintenance Treatment for Flexible Pavements. Report FHWA-IF-00-027. Federal Highway Administration (FHWA), US Department of Transportation, Washington, DC. 96 p. Available from Internet: http://www.fhwa.dot. gov/pavement/pubs/013551.pdf

Indiana Logistics. 2008. Indiana Logistics Directory. Available from Internet: http://www.indianalogistics.com/directory

InDoT. 2011a. Average Daily Traffic and Commercial Vehicles: Interactive Map. Indiana Department of Transportation (InDoT), Indianapolis, IN. Available from Internet: https:// entapps.indot.in.gov/TrafficCounts

InDoT. 2011b. Indiana Design Manual. Chapter 52: Pavement and Underdrain Design Elements. Indiana Department of Transportation (InDoT), Indianapolis, IN. 138 p. Available from Internet: http://www.in.gov/dot/div/contracts/standards/dm/2011/Part5/Ch52/ch52.htm

InDoT. 2007. 2030 Long Range Transportation Plan. Chapter 8: Freight Transportation. Indiana Department of Transportation (InDoT), Indianapolis, IN. 16 p. Available from Internet: http://www.in.gov/indot/files/08_freight.pdf

Jain, K.; Jain, S. S.; Chauhan, M. S. 2014. Selection of optimum maintenance and rehabilitation strategy for multilane highways, International Journal for Traffic and Transport Engineering 3(3): 269-278.

http://doi.org/10.7708/ijtte.2013.3(3).04

Khurshid, M. B. 2010. A framework for Establishing Optimal Performance Thresholds for Highway Asset Interventions: PhD Dissertation. Purdue University, US. 288 p.

Khurshid, M. B.; Irfan, M.; Ahmed, A.; Labi, S. 2014. Multidimensional benefit-cost evaluation of asphaltic concrete overlays of rigid pavements, Structure and Infrastructure Engineering: Maintenance, Management, Life-Cycle Design and Performance 10(6): 792-810. http://doi.org/10.1080/15732479.2013.767842

Khurshid, M. B.; Irfan, M.; Labi, S. 2011. Optimal performance threshold determination for highway asset interventions: analytical framework and application, Journal of Transportation Engineering 137(2): 128-139. http://doi.org/10.1061/(ASCE)TE.1943-5436.0000198

Labi, S. 2001. Impact Evaluation of Highway Pavement Maintenance Activities: PhD Dissertation. Purdue University, US. $376 \mathrm{p}$.

Labi, S.; Lamptey, G.; Konduri, S.; Sinha, K. 2005. Pavement management: analysis of long-term effectiveness of thin hot-mix asphaltic concrete overlay treatments, Transportation Research Record: Journal of the Transportation Research Board 1940: 1-12. http://doi.org/10.3141/1940-01

Labi, S.; Sinha, K. C. 2003. The Effectiveness of Maintenance and its Impact on Capital Expenditures. Report FHWA/IN/JTRP2002/27. Indiana Department of Transportation, Indianapolis, IN. 466 p. Available from Internet: http://docs.lib. purdue.edu/cgi/viewcontent.cgi? article=1679\&context=jtrp 
Lamptey, G.; Ahmad, M.; Labi, S.; Sinha, K. C. 2005. Life Cycle Cost Analysis for InDoT Pavement Design Procedures. Report FHWA/IN/JTRP-2004/28. Indiana Department of Transportation, Indianapolis, IN. 263 p. Available from Internet: http://docs.lib.purdue.edu/cgi/viewcontent. cgi? article $=1609 \&$ context $=$ jtrp

Li, Z.; Kaini, P. 2007. Optimal Investment Decision-Making for Highway Transportation Asset Management under Risk and Uncertainty. Project 07-10. Research and Innovative Technology Administration, US Department of Transportation, Washington, DC. 208 p. Available from Internet: http:// minds.wisconsin.edu/bitstream/handle/1793/54132/07-10_ FR.pdf

Meneses, S.; Ferreira, A.; Collop, A. 2013. Multi-objective decision-aid tool for pavement management, Proceedings of the Institution of Civil Engineers - Transport 166(2): 79-94. http://doi.org/10.1680/tran.10.00026

MnDoT. 2001. Network level bituminous decision tree. Minnesota Department of Transportation (MnDoT), St. Paul, MN. Available from Internet: http://www.dot.state.mn.us

Ong, G. P.; Nantung, T.; Sinha, K. C. 2010a. Indiana Pavement Preservation Program. Report FHWA/IN/JTRP-2010/14. Indiana Department of Transportation, Indianapolis, IN. 108 p. Available from Internet: http://docs.lib.purdue.edu/ cgi/viewcontent.cgi? article $=2606 \&$ context $=$ jtrp

Ong, G. P.; Noureldin, S.; Sinha, K. C. 2010b. Automated Pavement Condition Data Collection Quality Control, Quality Assurance and Reliability. Report FHWA/IN/JTRP-2009/17. Indiana Department of Transportation, Indianapolis, IN. 158 p. Available from Internet: http://docs.lib.purdue.edu/ cgi/viewcontent.cgi?article $=2636 \&$ context $=$ jtrp

Parida, M.; Aggarwal, S.; Jain, S. S. 2005. Enhancing pavement management systems using GIS, Proceedings of the Institution of Civil Engineers - Transport 158(2): 107-113. http://doi.org/10.1680/tran.2005.158.2.107

Peterson, D. E. 1985. Life-Cycle Cost Analysis of Pavements. Synthesis of Highway Practice, National Cooperative Highway Research Program (Book 122). Transportation Research Board, Washington, DC, US. 136 p.

Rangaraju, P. R.; Amirkhanian, S.; Guven, Z. 2008. Life Cycle Cost Analysis for Pavement Type Selection. Report FHWASC-08-01. South Carolina Department of Transportation, Columbia, SC. 141 p. Available from Internet: http://www. clemson.edu/t3s/scdot/pdf/projects/SPR656Final.pdf

SAS Institute. 2016. SAS 9.4 Product Documentation. Available from Internet: http://support.sas.com/documentation/94

Sayers, M. W.; Karamihas, S. M. 1998. The Little Book of Profiling: Basic Information About Measuring and Interpreting Road Profiles. University of Michigan, US. 102 p. Available from Internet: https://deepblue.lib.umich.edu/handle/2027.42/21605

Smith, R.; Freeman, T.; Pendleton, O. 1993. Pavement Maintenance Effectiveness. Strategic Highway Research Program. Research Report SHRP-H-358. National Research Council, National Academy of Sciences, Washington, DC. 365 p. Available from Internet: http://onlinepubs.trb.org/ Onlinepubs/shrp/SHRP-H-358.pdf

Wade, M.; DeSombre, R.; Peshkin, D. 2001. High Volume/High Speed Asphalt Roadway Preventive Maintenance Surface Treatments. Final Report SD99-09. South Dakota Department of Transportation, US. 151 p. Available from Internet: http://www.sddot.com/business/research/projects/docs/ SD1999_09_Final_Report.PDF
Zimmerman, K. A.; Grogg, M. G.; Bozkurt, D. 2002. Effects of Maintenance Treatments on Asphalt Concrete Pavement Management. Study SD2001-03 Final Report. South Dakota Department of Transportation, US. 101 p. Available from Internet: http://www.sddot.com/business/research/ projects/docs/SD2001_03_Final_Report.pdf

Žilionienè, D.; De Luca, M.; Dell'Acqua, G. 2013. Evaluation of climatic factors based on the mechanistic-empirical pavement design guide, The Baltic Journal of Road and Bridge Engineering 8(3):158-165.

http://doi.org/10.3846/bjrbe.2013.20 